\title{
DITCH THE PLASTIC TRINIDAD \& TOBAGO: THE DYNAMICS OF A MULTI-SECTORAL SCHOOL-COMMUNITY PARTNERSHIP
}

\author{
Rowena Kalloo, \& Shahiba Ali \\ School of Education, University of the West Indies (Trinidad and Tobago)
}

\begin{abstract}
In the Caribbean, the average person contributes about $5 \mathrm{~kg}$ of plastic waste per day, one of the highest in the world. However, for Trinidad and Tobago (TT) this is about $1.59 \mathrm{~kg}$. A 2018 report found TT produces roughly 200,000 tonnes of waste annually, with $25 \%$ coming from plastics, especially from single-use packaging plastic. Though 55\% of plastics end up in landfills, just 19\% is recycled. In light of this, TT is about to pass legislation to recycle, recover and re-use waste materials and encourages collaboration among NGOs, CBOs, the private sector and government agencies to educate the public on the impact of plastic waste on health and the environment. Such education is urgently needed as a national survey of secondary school population in 2016 found that just $63 \%$ possess a pro-environmental disposition and just $51 \%$ were environmentally literate. Involvement of all citizens, in particular, youth who will inherit this problem, is clearly needed to advocate for control and elimination of single use plastic.

Building environmental awareness of youth and their communities can be accomplished through advocacy in multi-sectoral partnerships, seen as beneficial to learning for sustainability. The success of such partnerships is contingent on the capacity of stakeholders to articulate a common vision, and negotiate issues of power, accountability and collaboration while being sensitive to cultural context. This study presents an analysis of a multi-sectoral partnership in a semi- rural district in TT. The partnership advocated for the replacement of single use plastic shopping bags with reusable bags, a project which took place over the course of one year. Partners included local and foreign universities, environmental agencies, secondary schools, and community members of the main partner school. Multi-sectoral partnerships which cross international borders then present unique challenges. The study sought to determine the structures and processes that facilitated the partnership, using a case study design.

Data was collected through Interviews of stakeholders, and analysis of artefacts (minutes of meetings, reports, events, and products). Initial themes emerging through thematic analysis included a common vision, equitable power sharing, camaraderie, agency, national and community visibility and status. Few studies of this nature have been done in TT or the Caribbean, and as such the study has potential for providing important understandings of tools and processes for enhancing school-community partnerships in the cultural context of small island developing states
\end{abstract}

Keywords: Multi-sectoral partnerships, environmental education, single-use plastics.

\section{Background}

The disposal of plastic waste is a global problem. For the Caribbean, whose oceans are the homes of protected marine species such as the Leatherback turtle, plastic bags within the ocean ecosystem are particularly dangerous. TT produces roughly 200,000 tonnes of waste annually, with $25 \%$ coming from plastics, especially from single-use packaging plastic (Ritchie \& Roser, 2018). TT encourages collaboration among NGOs, CBOs, the private sector and government agencies to educate the public on the impact of plastic waste on health and the environment (EMA, GORTT, 2018). Such education is urgently needed among youth who will inherit this problem. A 2016 national survey of the secondary school population found that just $63 \%$ possess pro-environmental dispositions and just $51 \%$ were environmentally literate (EMA, GORTT, 2016). However, partnerships between the numerous local environmental agencies are rare. Further, while schools are often stakeholders and beneficiaries of environmental programmes they are hardly engaged as partners with these agencies. 


\subsection{PAN: Protect and nurture Trinidad and Tobago}

In 2018 a partnership between local and international tertiary institutes, local schools, and environmental agencies coalesced under the sobriquet of PAN - Protect and Nurture the Environment Trinidad and Tobago. The Steel Drum which is referred to as the Pan, is the national instrument, and thus the acronym has special significance for the islands' cultural heritage, and the image of the steelpan is a central feature of the partnership's logo. PAN is an informal partnership which was triggered by the early service learning initiatives of an American University (AU) in 2009 and 2016. AU worked in partnership with Asa Wright Nature Centre (AWNC) - a leading environmental NGO. PAN launched its first project in 2018 and were able to successfully launch this project with the slogan, "Go Green Not Polythene". The highpoint of the project was a day of advocacy and education in a rural district. The day involved distributing flyers and reusable shopping bags, and culminated in an afternoon of environmental games at a local grocery where customers were rewarded with reusable bags. The strength of the partnership was such that the group was able to implement a second project in 2019, and is in the process for planning for its third project in 2021/2022. The authors of this study are University faculty and members of PAN. We were intrigued by a partnership that could cut across its many cultural differences to work collaboratively on behalf of the environment. Partnerships hold a great deal of promise for fulfilling the objectives of environmental advocacy (Birdlife International 2008; Tilbury \& Wortman, 2004). These partnerships, when they involve schools, are able to realise the goals of environmental education, namely, knowledge building, attitudinal and behavioural change. Partnerships, however, can pose several challenges such as, negotiating commitment, accountability, and power sharing (Eames \& Bolstad, 2004). The nature of PAN and its resilience led to questions on the nature and dynamics of the partnership, despite its cultural differences and institutional constraints.

\subsection{Defining partnerships}

Partnerships have been defined as "a process in which two or more organisations or groups work together to achieve a common goal and do so in such a way that they achieve more effective outcomes than by working separately" (p. 3, BirdLife International, 2008). Partnerships create synergy built on a shared vision, transparency and equity, which allow partners to combine resources, talents, attract financial and technical support, and bring together diverse perspectives to add value to local initiatives (Bird Life International, 2008; Tilbury \& Wortman, 2004). Partnerships take a plethora of structures from formal and informal to locally based to internationally formulated. Partnerships with schools have double goals of problem solving and youth development, and school partnerships for the environment find value in grounding their work in locally based and important problems for the school community (Monroe, et al., 2016). All partnerships are characterised by several complex psycho-social and value constructs which must be negotiated for effective problem solving and innovation. The skills of negotiation, accountability, relationship building, and resource and knowledge brokering, pattern recognition of stumbling blocks, are just some of the tools available to partners (Thomson \& Perry, 2006; Moore \& Wesley, 2011). Research has the capacity to unearth these often intuitive behaviours and values, and in so doing provide partnerships with the capacity to harness such tools consciously for their mutual benefit.

\section{Objectives of the study}

Environmental projects which have involved collaboration among schools, communities, NGOs and CBOs have been shown to be highly effective in their educational and advocacy roles. While such programmes exist across Trinidad and Tobago, few of them have been evaluated to understand the dynamics of collaborative partnerships for the environment. The purpose of this study is to understand the dynamics of a unique multi-stakeholder partnership which was organised around advocacy to end single plastic bag use in a semi-rural district in the island of Trinidad. The study sought to analyse the structures and processes that facilitated the partnership, using an in-depth case study design. The study raised the question: What were the processes and structures which facilitated a multi-stakeholder, school-community partnership for environmental advocacy (the GGNP project), in a semi -rural district in Trinidad and Tobago? The findings of this study have potential for providing important understandings of structures and processes which facilitate school-community partnerships in the cultural context of small island developing states.

\section{Methodology}

This research adopted a qualitative approach to investigating the complex issue of a multi-stakeholder school-community partnership advocating against single use plastic grocery bags. Adhering to an interpretivist worldview, we chose a single case study design, which is descriptive in 
nature. A case study affords an in-depth analysis of an issue. The case is the PAN partnership structure, and the processes that brought about its formation and sustainability. We sought to explore and understand the meaning of the experiences of participants as they planned and executed the GGNP project established through the PAN partnership. We drew on a broad range of data collection methods - interviews, observations, documents, and a survey. The survey was an open-ended 14 item questionnaire which interrogated participants' motivation and experience of the project. With their permission, 11 participants of the PAN partnership agreed to engage in the research. Documents of minutes of all meetings and emails were sourced for the period of the GGNP project (March 2017- February 2018). The primary researcher was involved in all stages of the project and brought her observations of the project as a source of data. Seven participants, representing 5 organisations, responded to the survey questionnaire administered online. Follow-up interviews were conducted with some of these participants to clarify views expressed in the survey. Data analysis was done through inductive content analysis, arriving at the themes through open, axial and selective coding with reference to the literature. Limitations of this single case study are researcher subjectivity, generalizability to the wider population, and being difficult to replicate.

\section{Findings}

The following themes (in bold) emerged from interrogation of the data:

An evolution from Service Learning to Partnership: The concept of PAN emerged at the first meeting of an ad hoc group of 13 representatives, including environmental NGOs and educators in March 2017. The American University Professors shared the results of their 2016 service learning initiative with the expectation that representatives at the meeting would provide insight on the way forward for their next project in 2018. The rich discussion that ensued provided an understanding of the breadth of initiatives already at work in Trinidad and Tobago, as well the role of environmental education in local schools. Participants decided to create a coordinating committee comprising several of the attendees who committed themselves to a follow up meeting. In the mix was the idea of birthing a multi-sectoral environmental partnership already in conceptualisation by AWNC under the sobriquet - PAN (minutes of 20th March 2017). By the second meeting of the group on April 4th, the dynamics of the group began to be established and roles emerged organically. This meeting was a conversation for visioning. Within the group there were several knowledge brokers, who were able to bring to the table in-depth information on the state of the environmental waste management in Trinidad and Tobago. The idea of PAN as a viable organisation project was established and the need to develop a logo and clear mission statement linked to sustainability was requested. The discussions among the group led to a series of actions and persons volunteered to fulfill the actions and committed to the next meeting. It was clear that there was no friction between members of this group. A democratic culture had quickly established itself. There was clearly a sense of camaraderie; these were people who felt comfortable with each other. In the survey participants describe their PAN colleagues as "wonderful and committed", enjoying working with "diverse backgrounds" and "passionate" people. They were moving towards a common goal, though exactly how this goal would be fulfilled was not yet established.

\subsection{Establishing group dynamic}

The second meeting was a cornerstone in partnership formation. It established the core group, the roles of its members; its modus operandi, its vision and its decision making structure. Each member of this group represented a source of expert knowledge, and garnered unsolicited respect. Emerging from this meeting was a culture of mutual decision making through knowledge brokering and visioning, and a culture of voluntarism. It was a culture that led to ownership of the project and one which allowed individual members to fulfill both personal and organisational goals while working towards a common purpose. The following themes emerged as characterising its modus operandi: Visioning as a democratic activity, Voluntarism, Public sharing of knowledge, Networking, Knowledge and Resource Brokering. It took a full 11 months from the second meeting for the culmination of the GGNP initiative. During this time the group met every month sometimes twice a month using the format and procedures established in the cornerstone meeting of April 04th. The project evolved from an amorphous desire of addressing pollution through education, advocacy and community action into a solid plan with distinct objectives, and activities. Each decision involved discussions, and ability to compromise, a willingness to listen to the other, and a commitment to voluntarily take on a task. These observations were supported by the survey results which identified collaboration and consensus as the decision making processes. 


\subsection{Roles and responsibilities}

Emerging from the data (minutes) were the organic evolution of partner roles and responsibilities. Each individual voluntarily took on a role that they had both the skills and resources to accomplish. These roles included: Repository and logistic facilitator: AWNC took on this role. Their remit as an environmental NGO was networking, advocacy and education and they therefore had the tools to fulfill this mandate. As such this NGO acted as an important logistical pivot that kept the momentum of the initiative alive across international borders. Resource brokers: The American University was the partner with most access to finances and various levels of expertise. At a local level several of the PAN members were instrumental in sourcing local resources and networking: School and community liaisons and organisers: A critical aspect of the GGNP project was the involvement of the rural school and its community, as well as a traditional, academic oriented urban school. The service learning component of the AU wished to facilitate a meeting of AU teachers and local schools. These secondary school students and their teachers were the conduit through which PAN believed that sustainable attitudinal change sustainable would emerge. Public Liaison: This member used their networking and contacts to provide the publicity for the event. This gave the walk-about event a certain amount of public accolade and status which transferred to the schools and their students. Resource support: Other members acted as resource support pitching in where and whenever needed.

\subsection{Psycho-social rewards}

A second factor which played into the development of agency - that empowerment to act without coercion - were the psycho-social rewards of involvement in such an initiative. This factor emerged through an analysis of the survey and interviews. Respondents spoke to the satisfaction they received through involvement - "a wonderful experience getting to know people and agencies... seeing the impact of change in attitude... and the impact of the project on students,". The survey also confirmed the strength of a common vision which was strongly impacted by the need to influence youth, and to create an authentic service learning experience through community partners. For these partners the challenges lay in juggling their personal commitments with the time demands of the project, and they noted the important role that technology played in lessening this form of stress. The few challenges identified reflect the strength of this partnership and the positive effect the project seemed to exert on its participants. The dynamics of the PAN partnership reflected the strengths of partnerships described in the literature - that is the synergy that a common goal and democratic decision process exert on agency and personal satisfaction.

\section{Conclusion}

The project provides a lesson on how even in limited financial circumstances, a diverse community can broker its expertise, resources, knowledge, and finances to work on an authentic and significant environmental project, and experience a sense of personal satisfaction and accomplishment which creates resilience and sustainability in multi-stakeholder partnerships.

\section{References}

BirdLife International. (2008). Building Partnerships: Working together for conservation and development. Cambridge, UK: BirdLife International.

Clapp, J., Swanston, L. (2009). Doing away with plastic shopping bags: International patterns of norm emergence and policy implementation, Environmental Politics, 18 (3): 315-332.

Coe, M. (2015). Research Brief - Summary: Building Capacity for Integrating Environmental Education with Community Empowerment: Interviews with Leaders in the Portland Metro Area. Portland, Oregon, US: Cedar Lake Research Group LLC.

Eames, C., \& Bolstad, R. (2004). The Role of partnerships in environmental education in New Zealand schools- some findings from a recent research project. Paper presented at the 2004 New Zealand Association for Environmental Education (NZAEE) conference, Christchurch College of Education, 14-17, January. Retrieved from http://www.nzcer.org.nz/pdfs/12819.pdf

Environmental Management Authority. (2016). National Environmental Literacy Survey. Ministry of Planning and Development, Government of the Republic of Trinidad and Tobago.

Environmental Management Authority. (2018). National Environmental Policy of Trinidad and Tobago. Ministry of Planning and Development, Government of the Republic of Trinidad and Tobago. 
Government of the Republic of Trinidad and Tobago. (2018). A world environment day message, "Beat Plastic Pollution" by Senator, the Honourable Rober Le Hunte, Minister of Public Utilities. Retrieved from: http://www.mpu.gov.tt/home/node/262

Hands, C. (2005). It's Who You Know and What You Know: the Process of Creating Partnerships Between Schools and Communities. The School Community Journal, 15(2): 63-84.

Hands, C. (2010). Why collaborate? The differing reasons for secondary school educators' establishment of school-community partnerships, School Effectiveness and School Improvement, 21(2): 189-207.

Hands, C. (2015). Creating Links between the School and the Community Beyond its Walls: What Teachers. Teaching \& Learning, 9(1): 1-15.

Monroe, C. M., Ballard, L.H., Oxarart, A., Sturtevant, E.V. Jakes J. P., \& Evans, R.E. (2016). Agencies, educators, communities and wildfire: partnerships to enhance environmental education for youth. Environmental Education Research, 22(8):1098-1114.

Moore, M., \& Westley, F. (2011). Surmountable chasms: networks and social innovation for resilient systems. Ecology and Society, 16(1): 5. Retrieved from: http://www.ecologyandsociety.org/vol16/iss1/art5/.

Public Administration Review, 66: 26-32.

Ritchie, H. \& Roser, M. (2018). "Plastic Pollution". Retrieved from: https://ourworldindata.org/plasticpollution.

Thomson, A., Perry, L. J. (2006). Collaboration processes: inside the black box.

Tilbury, D., Wortman, D. (2004) Engaging People in Sustainability, Commission on Education and Communication, Gland, Switzerland: IUCN Publications Services Unit

World Environment Day Outlook. (2018). The State of Plastics Report. Retrieved from: https://www.unenvironment.org/resources/report/state-plastics-world-environment-day-outlook2018 